\title{
Patterns of Socio-economic Deprivation and its Impact on Quality of Life: Case of a Less Developed Region in West Bengal, India
}

\author{
By Basudatta Sarkar* \\ Haimanti Banerji ${ }^{\dagger}$ \\ Joy Sen
}

In the current context of regional planning, the issue of socioeconomic deprivation and its impact on quality of life is becoming highly significant. Though several regions in cities and their fringe areas are continuously developing, but the community development blocks of various sub regions in them exhibit a fairly evident pattern of dichotomy and duality in development. Consequently, the sub regions become more socio-economically susceptible and more prone to vulnerability compared to the cities having a higher level of preparedness in development. The key reason is the unequal distribution of national assets and resources across the systems of sub regions. Hence, there is a need to evaluate the degree of susceptibility in the different sub regions. The susceptibility in the process of development can be spatially explained by studying the patterns of deprivation in the sub regions. Additionally there is an observation on quality of life in terms of poor physical infrastructure and housing conditions, which has bearing with susceptibility. The present paper tries to identify the patterns of deprivation and its impact on quality of life from the two observations. The study has been performed based on the performances of fifteen socio-economic growth indicators, broadly categorized as health, education and economic indicators following Human Development Index (HDI) guidelines. The patterns of deprivation of a sub region have been identified by calculating the distribution of deprivation index across the region. Finally, the paper has tried to understand the nature of relationship between deprivation index and quality of life indicators. There is a specific case of Malda, a comparatively less developed region of West Bengal which has been selected as the case study to best forward the concerns of the paper.

\footnotetext{
${ }^{*}$ Senior Research Fellow, Department of Architecture and Planning, Indian Institute of Technology Kharagpur, India.

${ }^{\dagger}$ Assistant Professor, Department of Architecture and Planning, Indian Institute of Technology Kharagpur, India.

"Professor, Department of Architecture and Planning, Indian Institute of Technology Kharagpur, India.
} 


\section{Introduction}

\section{Background of the Study}

The term deprivation stands for the condition of a system or a community or a region which is lacking the basic necessities of a society or community. Analogically, socio-economic deprivation can be described as the lack of social and economic benefits which are considered to be basic necessities of a society or community or in a broader sense of a region. The regions with high demand and low supply of basic requirements often exhibit poor social and economic status compared to the other adjacent regions which mark the former as socioeconomically deprived region (Pampalon et al., 2000).

According to Maslow's hierarchy of needs, the basic necessities refer to the food, shelter and warmth (Maslow, 1943). The development of any region primarily depends on the fulfillment of these three prime factors. But practically, it is difficult to measure the development of any community or regional system only in terms of availability of food, shelter and warmth. The fundamental factors have to be more specific and quantified to assess the degrees of deprivation. Therefore a set of quantitative indicators which collectively represent the three prime factors of development need to be identified to measure the overall development of any regional system. In the present study, to identify the pattern of socio-economic deprivation, the Human Development Index (HDI) indicators have been considered as the primary units of measurement. Human Development Index (HDI) is considered worldwide as a basic yardstick for the measurement of socio-economic development, whose fulfillment satisfies the reaching of "A composite index measuring average achievements in three basic dimensions of human development- a long and healthy life, knowledge and a decent standard of living" (Human Development Reports, 2003). The performances of HDI based indicators also reflect the quality of life of people of any particular region. As example, it can be stated that low per capita income (economic indicator) leads to poor quality of housing, high illiteracy rate (knowledge indicator) leads to less awareness, less number of doctors and beds in hospitals (health indicator) leads to poor health condition etc. Performances of the indicators determine the state of deprivation and in a larger scale the pattern of deprivation for the whole region.

There are several other vicious causal factors which act upon a region and make significant diverse changes in the performances of the indicators. The impact of the factors upon any regional system can be fatal as they expose the region towards different kinds of social and economic shocks, which in turn make a socio-economically deprived region highly sensitive. The factors can be of different types and can emerge from different dimensions. They can damage in direct and indirect way to both tangible as well as intangible assets and eventually affect the quality of life of the people living in the affected region. The extent of damage depends on the nature and intensity of shocks generated by them (Kim et al., 2009). This paper has primarily referred to a set of causal factors proposed by different researchers shown in Table 1. 
Table 1. Causal Factors

\begin{tabular}{|c|c|}
\hline Source & Causal factors \\
\hline $\begin{array}{l}\text { Kelly and } \\
\text { Schmidt, } 1995\end{array}$ & $\begin{array}{l}\text { Poorly developed market and institutional systems, high } \\
\text { dependency rate, and relative unimportance given to } \\
\text { aggregate demand }\end{array}$ \\
\hline $\begin{array}{l}\text { Loughead et al., } \\
2001\end{array}$ & The limited or no access to the common property \\
\hline $\begin{array}{l}\text { Alcant } \\
2002\end{array}$ & $\begin{array}{l}\text { Lack of access to resources, disintegration of social patterns, } \\
\text { lack of strong national and local institutional structure, lack of } \\
\text { public awareness, limited access to political power and } \\
\text { representation, and certain beliefs and customs }\end{array}$ \\
\hline $\begin{array}{l}\text { Ellis F., } \\
\text { Freeman A. H., } \\
2004\end{array}$ & $\begin{array}{l}\text { Unemployment and gender differentiation in work places, } \\
\text { macro-micro linkages, transformation of rural assets into } \\
\text { money, disadvantageous position of women in urban food and } \\
\text { labour market }\end{array}$ \\
\hline Sastry, 2004 & $\begin{array}{l}\text { Poverty, transformation of farm land into urban land, change } \\
\text { in the labour force participation pattern }\end{array}$ \\
\hline $\begin{array}{l}\text { Briguglio et al, } \\
2006\end{array}$ & Opening to the elements of the exogenous shocks \\
\hline $\begin{array}{l}\text { Holmes et al., } \\
2010\end{array}$ & $\begin{array}{l}\text { Diversion of mean of earning from agriculture to non-farm } \\
\text { activities, low household income }\end{array}$ \\
\hline Pasteur, 2011 & Selling assets like land and livestock \\
\hline $\begin{array}{l}\text { Sarkar et al., } \\
2012\end{array}$ & $\begin{array}{l}\text { Price change of certain commodity affecting the economy of } \\
\text { people, economic recession, technological changes, a major } \\
\text { change in Government policy decision, a major political } \\
\text { turnover, a change in taxation policy, any new law or } \\
\text { amendment of an existing law }\end{array}$ \\
\hline
\end{tabular}

In Indian context, the study on socio-economic deprivation is gradually becoming significant due to the pressure created over the sub regions by rapid urbanization, changing pattern of demand and supply, globalization etc which have created different layers in the process of development. In the present context the level of development can be explained in three layers of development- development in cities, development in fringe areas and development in community development (CD) blocks. The cities are already developed and resourceful. The fringe areas are trying to be a part of city to avail all the amenities in full fledged manner and therefore they are gradually developing. But the area of concern is the development level of CD blocks. Most of the times, the CD blocks being the most neglected part of a region face the highest level of deprivation in social as well as economic aspects. This negligence often leads towards multiple deprivations in both social and economic dimensions Therefore, in order to understand the pattern of deprivation, the present study has considered the community development blocks as the spatial unit forming the sub regions. 
Need of the Study

It has been established in previous research works, that social and economic benefits are the basic necessities of a region and lack of the same makes that particular region exposed to different kinds of shocks and injuries. The region becomes highly sensitive and susceptible in response to the socioeconomic shocks generated by the causal factors. When the susceptibility of the sensitive regions exceeds certain limit of tolerance, they become vulnerable to the similar kind of shocks. Secondly, the quality of life of people living in CD blocks is of major concern. Poor and degraded quality of life is a very common phenomenon in those regions. The present study not only attempts to understand the pattern of socio-economic deprivation in the CD blocks of a relatively less developed region in West Bengal, but also tries to explore the existence of any relationship between the pattern of socio-economic deprivation and poor quality of life. Since, the present study has referred to the HDI based indicators for measurement of deprivation, the investigation unveiling the relationship of socio-economic deprivation and poor quality of life becomes obvious. Accordingly, the following two objectives have been formulated to accomplish the present study:

- To identify the pattern of socio-economic deprivation

- To understand the relationship of socio-economic deprivation and poor quality of life

\section{Methods}

\section{Case Study Region}

To fulfill the objectives, Malda- a relatively less developed region in West Bengal, located in eastern part of India has been chosen as the case study. Malda is a district in West Bengal centrally located in the riparian zone of river Ganges (Figure 1). All CD blocks within it have some commonality in terms of soil type, spatial characteristics, demographic and socio-economic characteristics. The region is less addressed and underdeveloped in both agriculture and industrial sectors and consequently is lacking in basic social and economic necessities (Shamim and Ahmed, 2011). Low agricultural productivity, small size of land holding, high dependency on farming, drought and flood are the additional factors acting behind the state of underdevelopment (Siddiqui and Hussain, 2010). 
Figure 1. Location of Case Study Region

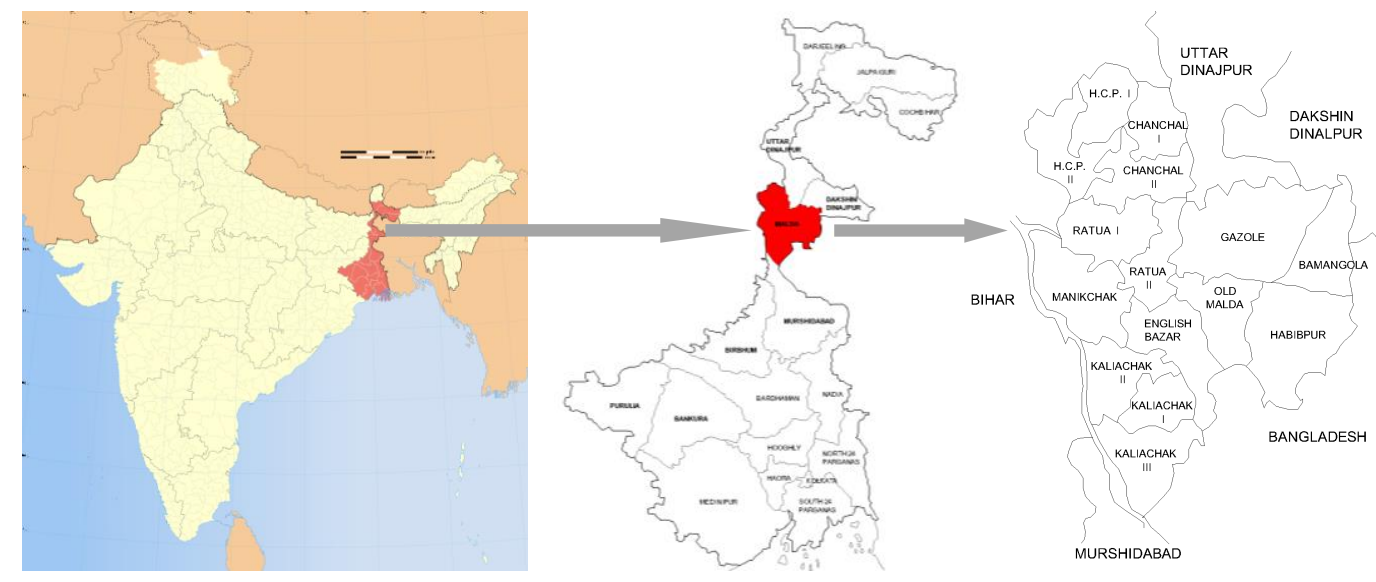

\section{Tools and Techniques}

For identification of the pattern of deprivation, the standard formula of indices of multiple deprivations has been used to identify the deprivation index for each CD block in the case study region. As per the definition given by Peter Townsend (1987), deprivation can be explained as "a state of observable and demonstrable disadvantage relative to local community or the wider society or nation to which the individual, family or group belongs". Broadly, it can be classified into two categories- material and social, indicating lack of access to the basic necessities and social weakness respectively (Pampalon et al., 2012). The state of deprivation in any region or community can be measured by deprivation index. Deprivation index is considered as a geographical marker which indicates the quality of life of people (Pampalon et al., 2009). Multiple deprivation has been considered as sum total of different dimensions of deprivation (Noble et al., 2006). In the present study, the dimensions of deprivation refer to the three basic dimensions of HDI- health, knowledge and economy. Since, the primary units of study must be as small as possible so that it can ensure a very high level of accuracy (Pampalon et al., 2000), in this study, depending upon the availability of data, CD blocks have been considered as the smallest units. After calculation of the deprivation index a mapping has been done to visually represent the pattern of deprivation. The formula for indices of multiple deprivations is as follows:

$\mathrm{I}_{\mathrm{ij}}=\left(\mathrm{I}_{\max }-\mathrm{I}_{\mathrm{i}}\right) /\left(\mathrm{I}_{\max }-\mathrm{I}_{\min }\right)$

$\mathrm{I}_{\mathrm{ij}}=$ Deprivation Index of $\mathrm{i}^{\text {th }}$ variable in $\mathrm{j}^{\text {th }}$ unit of study

$I_{i}=$ value of $i^{\text {th }}$ variable in $j^{\text {th }}$ unit of study

$I_{\max }=$ Maximun value of $i^{\text {th }}$ variable

$I_{\min }=$ Minimum value of $i^{\text {th }}$ vatiable

Indices of Multiple Deprivations

$\mathrm{DI}=\Sigma \mathrm{I}_{\mathrm{ij}} / \mathrm{n}$

$\mathrm{n}=$ Total number of variables 
For the second objective, the deprivation indices have been related with the quality of life indicators and the relationship has been graphically represented for the detailed illustration. The relationship has been explained with the help of Pearson's correlation coefficient. It is a measure of correlation between different variables explaining their dependence up on each other. The correlation coefficient is generally delineated by ' $r$ '. The value of $r$ ranges from +1 to -1 . Variables with the value near to \pm 1 are considered to have very strong relationship with each other. The graphical illustrations have been made based on the z-scores of the QoL indicators and DI of each category of deprivations.

\section{Results}

\section{Selection of Indicators for Deprivation Index}

The selection of indicators has emerged as the key concern of the study as the performances of the indicators are going to determine the degree of deprivation in every single unit of study. Therefore the indicators have to be selected with extreme attention so that they can interpret the actual socioeconomic setting of the study region. As the present study from the very beginning has been emphasizing on the Human Development Index based indicators to best describe the social and economic scenario of any region, the three major dimensions have been conceived to frame a guideline for indicator selection. These three dimensions are- health, knowledge and economy.

For the initial selection of indicators, an exhaustive literature survey has been carried out from which an inventory of most appropriate indicators has been made. The inventory has been detailed out in Table 2 where the list of indicators has been produced along with the sources.

Table 2. Initial List of Indicators

\begin{tabular}{|c|c|}
\hline Source & Indicators \\
\hline \multirow{16}{*}{ World Bank } & Per capita expenditure on health \\
\hline & Under 5 mortality rate \\
\hline & Crude birth rate \\
\hline & Per capita expenditure on education \\
\hline & Literacy rate \\
\hline & Number of school teacher \\
\hline & Expected years of schooling \\
\hline & Enrolment/ number of students \\
\hline & Gross National Income per capita \\
\hline & Per capita income \\
\hline & Below Poverty Line population \\
\hline & Total population \\
\hline & Labour force participation \\
\hline & Telephone subscribers \\
\hline & Gross Domestic Product \\
\hline & Consumption \\
\hline
\end{tabular}




\begin{tabular}{|c|c|}
\hline \multirow{4}{*}{ National Sample Survey } & Labour force participation rate \\
\hline & Worker population ratio \\
\hline & Proportion unemployment \\
\hline & Unemployment rate \\
\hline \multirow{5}{*}{ Steinführer et al., 2009} & Low income group population \\
\hline & Disabled population \\
\hline & Recent migration \\
\hline & Vulnerable housing \\
\hline & Older population \\
\hline \multirow{15}{*}{ Eakin et al., 2008} & Age \\
\hline & Education level \\
\hline & Adult education level \\
\hline & Number of adults in households \\
\hline & Total area \\
\hline & Livestock \\
\hline & Irrigated area \\
\hline & Tractor \\
\hline & Land rental \\
\hline & Farm tenure \\
\hline & Credit \\
\hline & Insurance \\
\hline & Technical assistance \\
\hline & Climate information centre \\
\hline & Area in crops \\
\hline \multirow{8}{*}{ Tapsell et al., 2005} & Age \\
\hline & Gender \\
\hline & Employment \\
\hline & Occupation \\
\hline & Education level \\
\hline & Household composition \\
\hline & Type of housing \\
\hline & Number of rooms per households \\
\hline \multirow{7}{*}{ Cutter et al., 2003} & Personal wealth \\
\hline & Age \\
\hline & Density of built environment \\
\hline & Housing stock and tenancy \\
\hline & Occupation \\
\hline & Infrastructure dependence \\
\hline & Single sector economic dependence \\
\hline
\end{tabular}

After the initial compilation, the indicators are fitted into the given three dimensions. At the same time, three more parameters for selecting the indicators have been applied to identify the final set. They are: i. Data availability on local scale, ii. Exclusion of factors that do not affect vulnerability level within the case study region and iii. No interlink among factors. The final set of indicators has been enlisted in the Table 3. 
Table 3. Final Set of Indicators

\begin{tabular}{|c|c|c|}
\hline Health & Knowledge & Economy \\
\hline Under five mortality rate & Illiteracy rate & Unemployment rate \\
\hline Crude birth rate & Teacher in primary school & Commercial banks \\
\hline Beds in hospitals & $\begin{array}{c}\text { Enrollment in primary } \\
\text { school }\end{array}$ & Rural banks \\
\hline Polio vaccination & No. of primary school & $\begin{array}{c}\text { Net collection from small } \\
\text { savings }\end{array}$ \\
\hline Patients treated & & Co-operative society \\
\hline & & Fair price shop \\
\hline
\end{tabular}

\section{Pattern of Deprivation}

The pattern of deprivation has been identified by calculating the deprivation index (DI) for each unit of study that is for each CD block of the case study region. The values of the deprivation index of the CD blocks represent the spatial distribution of deprivation. To calculate the deprivation index the data have been collected from the Census of India, 2011 (http://censusindia.gov.in/) and District Statistical Handbook, Malda (2011). The Census of India is published from the Directorate of Census Operations, Govt. of India and District Statistical Handbook is published by the Bureau of Economics and Statistics, Govt. of India. The raw data for each indicator has been standardized by calculating the z-score. Then the z-score of each indicator has been put into the formula of indicaes of multiple deprivations. Finally the average deprivation index for all the CD blocks has been identified. Table 4 shows the deprivation index of each block.

Table 4. Deprivation Index

\begin{tabular}{|c|c|}
\hline CD Blocks & Average DI \\
\hline Bamongola & 0.878 \\
\hline Old Malda & 0.785 \\
\hline Chanchal I & 0.768 \\
\hline Ratua II & 0.751 \\
\hline Chanchal II & 0.748 \\
\hline Harishchandrapur I & 0.744 \\
\hline Kaliachak II & 0.723 \\
\hline Habibpur & 0.683 \\
\hline Harishchandrapur II & 0.674 \\
\hline Ratua I & 0.634 \\
\hline Kaliachak III & 0.577 \\
\hline Manikchak & 0.539 \\
\hline Kaliachak I & 0.492 \\
\hline Gazole & 0.463 \\
\hline English Bazar & 0.275 \\
\hline
\end{tabular}


Depending upon the values of average DI, the blocks have been categorized in four groups. They are: very highly deprived (DI $>0.8$ ), highly deprived (0.6>DI>0.79), deprived $(0.3>\mathrm{DI}>0.59)$ and less deprived $(0>\mathrm{DI}>0.29)$ region to emphasize the pattern of deprivation. The categorization in detail shows that there is only one block (Bamongola) which is very highly deprived, nine blocks are highly deprived, four blocks are deprived and only one block is less deprived which means a major part of Malda district is highly deprived in both social and economic dimensions. Only one block is categorizedas less deprived which is a major issue of concern. The pattern reveals the existing socio-economic status of the whole case study region that is the district of Malda. The spatial distribution of deprivation has been shown in Figure 2.

\section{Figure 2. Pattern of Deprivation}

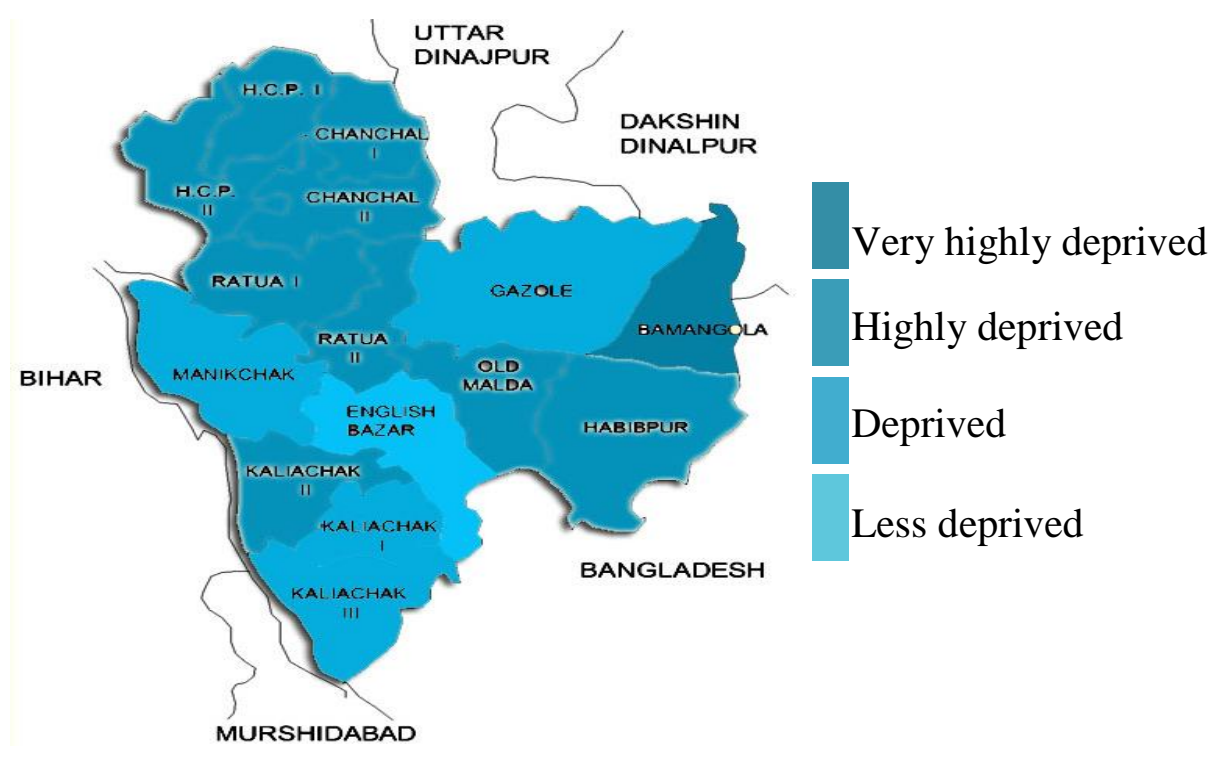

\section{Selection of Quality Of Life Indicators}

Quality of life (QoL) is the overall wellbeing of people and society and has a very wide range of contexts ranging from health to politics, economy to psychology, education to environment and leisure to social belongings (Gregory et al., 2009; Nussbaum and Sen, 1993). The World Health organization (WHO) defines QoL as : "an individual's perception of their position in life in the context of the culture and value systems in which they live and in relation to their goals, expectations, standards and concerns. It is a broad ranging concept affected in a complex way by the person's physical health, psychological state, personal beliefs, social relationships and their relationship to salient features of their environment" (http://www.who.int/men tal health/media/68.pdf). Therefore it is difficult to identify a particular set of indicators. Since the present study is more focused on socio-economic deprivation, authors have considered housing condition and physical 
infrastructural facility indicators as the micro level QoL indicators. The final set of QoL indicators are enlisted in Table 5.

Table 5. Quality of Life Indicators

\begin{tabular}{|c|l|}
\hline Category & \multicolumn{1}{|c|}{ Indicators } \\
\hline Housing condition & Number of households living in temporary housing \\
\hline \multirow{3}{*}{ Physical infrastructure } & Number of households having toilet and bathroom \\
\cline { 2 - 2 } & Number of households having drainage \\
\cline { 2 - 2 } & Number of households having electricity \\
\cline { 2 - 2 } & Number of households having water supply \\
\hline
\end{tabular}

\section{Impact of Deprivation over Quality of Life}

To understand the impact of deprivation over QoL, the correlation coefficients for DI and all QoL indicators have been determined. The values explain the very strong relationship between DI and QoL indicators. The correlation coefficients are shown in Table 6. Total number of households in study area is $8,46,991$ and total population of study area is $39,88,845$ (http://censusindia.gov.in/).

Table 6. Correlation of DI and QoL

\begin{tabular}{|c|c|c|c|c|c|}
\hline DI & $\begin{array}{c}\text { Number of } \\
\text { households } \\
\text { living in } \\
\text { temporary } \\
\text { housing }\end{array}$ & $\begin{array}{c}\text { Number of } \\
\text { households } \\
\text { having toilet } \\
\text { and bathroom }\end{array}$ & $\begin{array}{c}\text { Number of } \\
\text { households } \\
\text { having drainage }\end{array}$ & $\begin{array}{c}\text { Number of } \\
\text { households } \\
\text { having } \\
\text { electricity }\end{array}$ & $\begin{array}{c}\text { Number of } \\
\text { households } \\
\text { having water } \\
\text { supply }\end{array}$ \\
\cline { 2 - 6 } & 0.979 & -0.984 & -0.978 & -0.992 & -0.988 \\
\hline
\end{tabular}

To easily understand the relationship of deprivation with quality of life, a graphical illustration has been made. Five graphs have been drawn to show the nature of response of the quality of life indicators to the socio-economic deprivation. Figure $3(\mathrm{a}, \mathrm{b}, \mathrm{c}, \mathrm{d}$, and e) illustrates the results. The $\mathrm{X}$-axis represents the average deprivation index for all four patterns (Figure 2) of deprivation and $\mathrm{Y}$-axis represents the average $\mathrm{z}$-scores of quality of life indicators in the four differently deprived regions.

From the figures the observations drawn are:

Figure 3(a): Number of temporary housing increases with high DI indicating very poor housing conditions in very highly and highly deprived regions.

Figure 3(b): Number of households with toilet and bathroom gradually decreases with the increase in DI indicating the lack of hygiene, poor health status and poor condition of living in the very highly and highly deprived regions.

Figure 3(c): Number of households with drainage facility gradually deceases with the high DI explaining the poor physical infrastructure leading towards poor quality of life in the region with high deprivation. 
Figure 3(d): Number of households with electricity decreases with the increase in DI indicating the poor infrastructural framework and lack of access to basic necessities leading towards poor quality of life in the highly deprived regions.

Figure 3(e): Number of households with water supply gradually decreases with the increase in DI explaining the lack of access to basic necessities, lack of proper physical infrastructure which leads towards poor living conditions in the regions with high deprivation.

Figure 3. DI and QoL Relationship

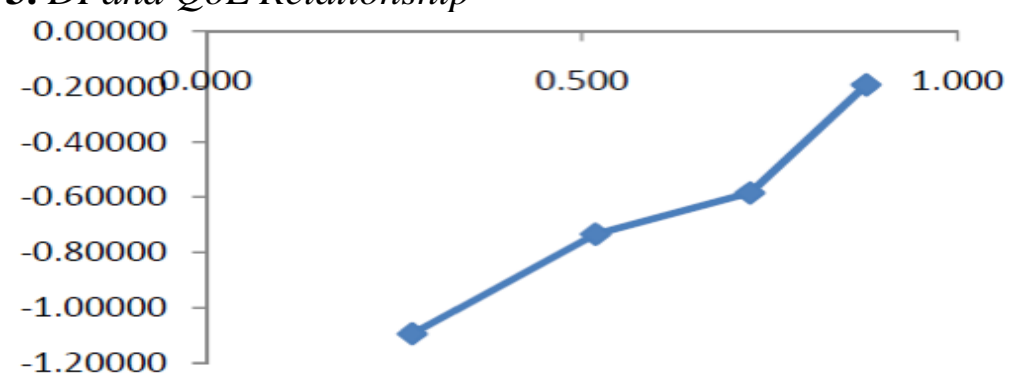

(a)

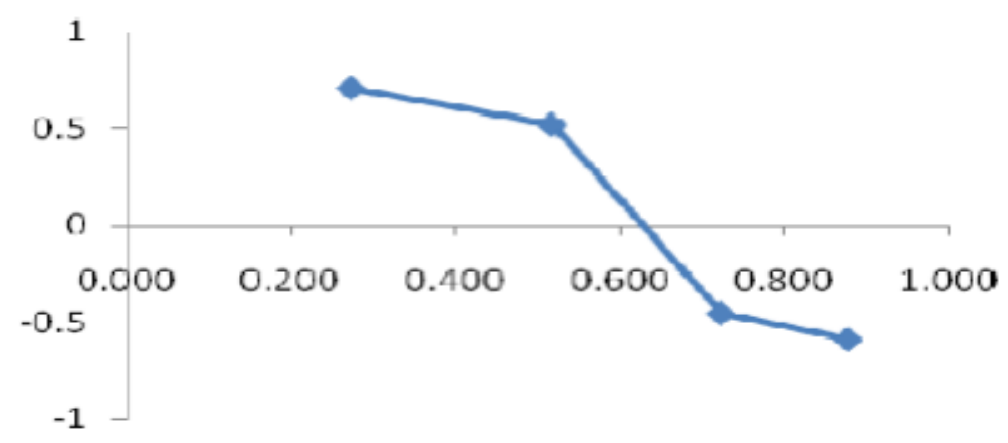

(b)

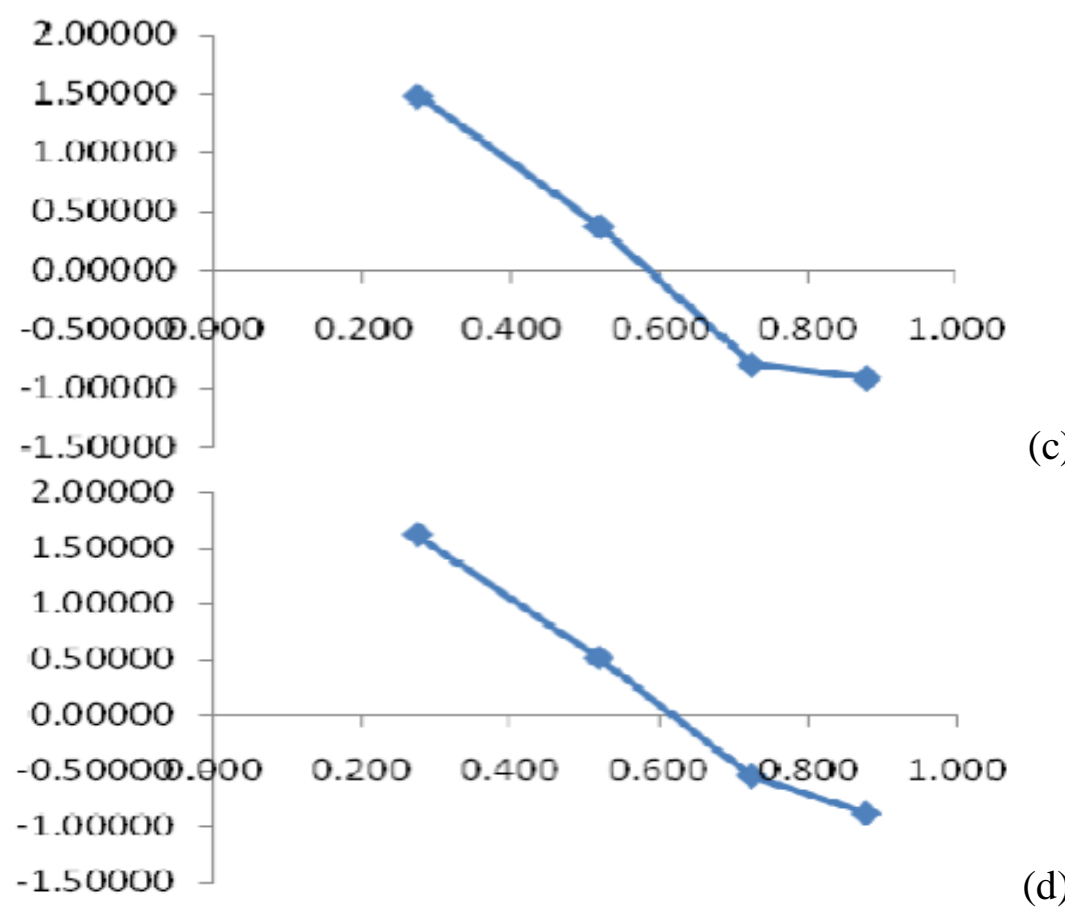




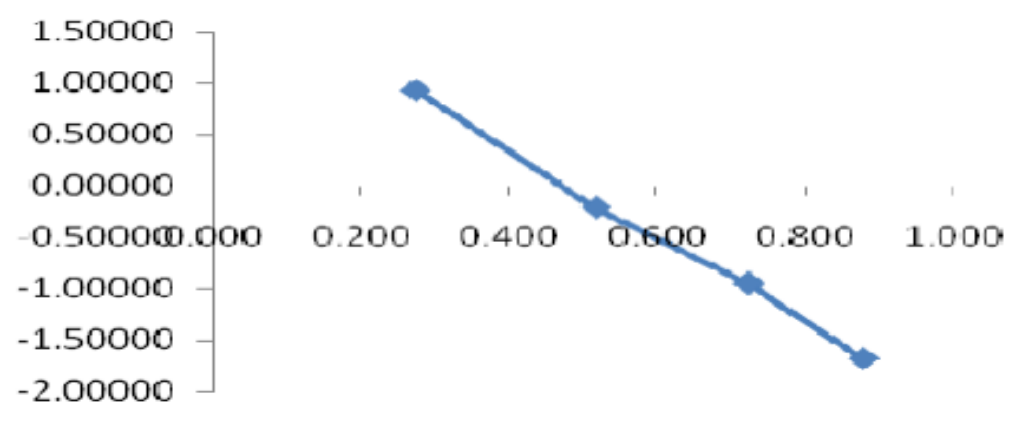

(e)

\section{Discussion}

The present study has tried to identify the pattern of socio-economic deprivation in a relatively less developed region and the impact of the socioeconomic deprivation over quality of life of that particular region. Earlier, in different researches it has been established that, deprivation index is considered as a widespread tool to understand the pattern and degree of socio-economic disparities (Drukker et al., 2003; Schuurman et al., 2007). Deprivation deals with various aspects causing lack of access to basic necessities and related resources which in turn affects the way of life (Nolan and Marx, 2009; Townsend 1979). Relevant researches in European countries have established that socio-economic deprivation and various dimensions of quality of life especially health related issues are associated with each other (Drukker and Os, 2003; Drukker et al., 2003). A study by Drukker et al. (2003) has revealed the relationship between socio-economic status and health related quality of life in The Netherlands. Moreover, the study has shown that, with the little variation in socio-economic deprivation, there is change in quality of life.

The vast application of the method has been seen mostly in the health related studies. However in the present paper the authors have tried to apply the concept of deprivation in case of quality of life of people. Firstly, the results for pattern of deprivation show a high level of socio-economic deprivation in the entire Malda district. Also, the quality of life of people living in the case study region is not up to the mark according to the statistics obtained from different reliable sources like Census of India 2011 and District Statistical Handbook 2011. Secondly, the results (table 6) explaining the impact of socio-economic deprivation over quality of life show that with the increased value of deprivation index, the value of the quality of life indicators decrease. In case of all the five quality of life indicators namely, number of households living in temporary housing, number of households with toilet and bathroom, number of household with drainage, number of household with electricity and number of household with drinking water supply, have lower values with high deprivation index. This incident explains that with high deprivation index, the quality of life becomes poorer, meaning the direct relationship of deprivation and poor quality of life. Consequently, socio-economically deprived regions always lead a degraded quality of life in terms of poor housing qualities and poor physical infrastructure which may lead towards multidimensional vulnerability to different kinds of social, medical and economic shocks. 


\section{Conclusions}

The preset study has tried to understand the pattern of socio-economic deprivation in a relatively less developed region of developing nations. The study shows how the quality of life of people can be affected by deprivation and how the general idea of quality of life of a particular region can be made based up on the socio-economic status of the region. The strong level of association between the DI and QoL explains the appropriateness of the study. The study identifies the basis of socio-economic susceptibility and consequent vulnerability by understanding the pattern and relationship of deprivation and QoL in a developing region. However, deprivation index is not an individual level measure and also does not provide an descriptive framework. The study is applicable for any less developed region of developing nations. The indicators can be modified according to the nature of derivation and focus of the study.

\section{Acknowledgments}

Our thanks to Athens Institute for Education and Research for selecting our paper for the presentation in " 4 "th Annual International Conference in Urban Studies and Planning" held in Athens, Greece. The paper is a small part of the doctoral research pursuing by Basudatta Sarkar. We are also very much thankful to Indian Institute of Technology Kharagpur, India for providing financial support to attend the conference and institute research fellowship for the doctoral research.

\section{References}

Alcantara-Ayala, Irasema., 2002. Geomorphology, Natural Hazards, Vulnerability and Prevention of Natural Disasters in Developing Countries. Geomorphology 47,pp-107-124

Briguglio L., Cordina G., Bugeja S., Farrugia N., 2006. Conceptualizing and Measuring Economic Resilience. Economics Department, University of Malta.

Census of India, 2011. Published by Government of India.

Cutter S.L., Boruff B.J., Shirley W.L., 2003. Social Vulnerability to Environmental Hazards. Social Science Quarterly, Volume 84, Number 2

Drukker M., Kaplan C., Feron S., Os J., 2003. Children's health-related qualityof life, neighbourhood socio-economic deprivation and social capital: A contextual analysis. Social Science \& Medicine, vol 57, pp-825-841.

Drukker M., Os J., 2003. Mediators of neighbourhood socioeconomic deprivation and quality of life. Soc Psychiatry Psychiatr Epidemiol. Vol 38, pp-698-706.

Eakin, H. and Bojórquez-Tapia, L.A. (2008): Insights into the composition of household vulnerability from multicriteria decision analysis. Global Environmental Change 18 pp- 112-127.

Ellis F., Freeman A. H., 2004. Rural Livelihoods and Poverty Reduction Strategies in Four African Countries. The journal of development studies, vol.40, no.4, pp-1 30. 
Gregory D., Johnston R., Pratt G., Watts M, Whatmore s., 2009. Dictionary of Human Geography. Willey-Blackwell Publications, pp-606.

Holmes R., Sadana S., Rath S., 2010. Gendered Risks, Poverty and Vulnerability in India: Case Study of the Indian Mahatma Gandhi National Rural Employment Guarantee Act (Madhya Pradesh).Overseas Development Institute.

Human Development Reports, 2003. United Nations Development Programme.pp-341

Kelley C. A., Schmidt R.M., 1995. Aggregate Population and Economic Growth Correlation: The Role of the Components of Demographic Change. Demography, vol 32, no. 4, pp-543-555.

Kim S., Arrowsmith C. A., Handmer J., 2009. Assessment of socio-economic vulnerability of coastal Areas from an indicator based approach. Proceedings of the 10th International Conference on GeoComputation, University of New South Wales.

Loughhead S., Mittal O., Wood G., 2001. Urban Poverty \& Vulnerability in India. Department for International development.

Maslow A.H., 1943. A Theory of Human Need. Psychological Review, 50, pp- 370396.

Noble M., Wright G., Smith G., Dibben C., 2006. Measuring multiple deprivation at the small-area level. Environment and Planning A, volume 38, pp- 169 - 185

Nolan B., Marx I., 2009. Economic Inequality, Poverty, and Social Exclusion. In Salverda, Nolan, Smeeding 2009, pp. 315-341.

Nussbaum M., Sen A. (Edts), 1993. The Quality of Life. Clarendon Press.

Pampalon R, Raymond G., 2000. A deprivation index for health and welfare planning in Quebec. Chronic Dis Can volume 21(3), pp-104-113.

Pampalon R., Hamel D., Gamache P., 2009. A Deprivation Index for Health Planning in Canada. Institut National de Sante Publique.

Pampalon R. et al., 2012. An Area-based Material and Social Deprivation Index for Public Health in Québec and Canada. Can J Public Health 2012;103(Suppl. 2):S17-S22.

Pastuer K., 2011. From Vulnerability to Resilience: A Framework for Analysis and Action to Build Community Resilience. Schumacher centre for technology and development. Practical action publishing.

Sarkar B., Banerji H., Sen J., 2012. Strategies to Cope up Socio-economic Vulnerability for The Backward Regions in India. Spandrel. Issue 4. pp- 116-120.

Sastry N. S., 2004. Estimating Informal Employment \& Poverty in India. Discussion Paper- 7.

Schuurman N., Bell N., Dunn J.R., 2007. Deprivation Indices, Population Health and Geography: An Evaluation of the Spatial Effectiveness of Indices at Multiple Scales. Journal of Urban Health: Bulletin of the New York Academy of Medicine, Vol. 84, No. 4.

Shamim Md., Ahmed S.N., 2011. Backward Districts for Planning and Development in West Bengal. Resource Development and Environmental Change, Vol-III, pp75-98.

Siddiqui A. F., Hussain N., 2010. Analysis of Micro Level Socio-economic Disparities in Malda District, West Bengal. Asia Pacific Journal of Social Sciences, Vol. II (1), PP- 39-61.

Steinführer, A., De Marchi, B., Kuhlicke, C., Scolobig, A., Tapsell, S. and Tunstall, S 2009. Vulnerability, resilience and social constructions of flood risk in exposed communities. FLOODsite report T11-07-12, http://www.floodsite.net

Tapsell, S. M., Tunstall, S. M., Green, C. and Fernandez, A. 2005. Social indicator set. FLOODsite report T11-07-01 
Townsend P., 1987. Deprivation. J Soc Policy, vol 16, pp-125-46.

Townsend P., 1979. Poverty in the United Kingdom. Harmondsworth, Penguin

\section{Electronic Sources:}

http://censusindia.gov.in/

http://data.worldbank.org/indicator

http://en.wikipedia.org/wiki/Quality_of_life

http://mospi.nic.in/Mospi_New/site/inner.aspx?status=3\&menu_id=31

http://www.who.int/mental_health/media/68.pdf

http://www.floodsite.net/html/publications2asp?ALLdocs=on\&Submit=View, Enfield:

Flood Hazard Research Centre. 
